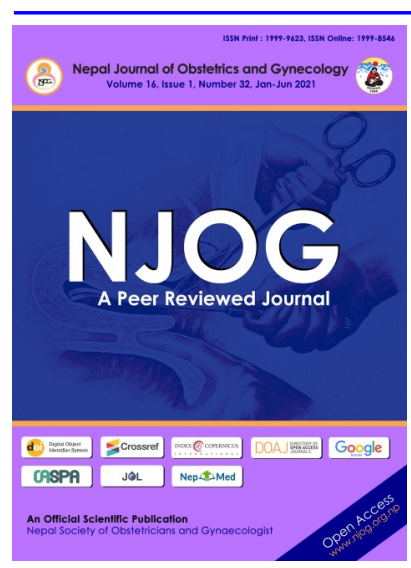

CORRESPONDENCE

Dr Tarun Pradhan

Department of Obstetrics and Gynaecology

Birat Medical College

Teaching Hospital,

Biratnagar

Email:

tarunsriti@gmail.com;

Phone: +977-9852056446

Received: March 26, 2021

Accepted: May 1, 2021

\section{Citation:}

Pradhan T, Deo A, Mahato RD, Basnet T. Pattern of Lower Urinary Tract Symp. toms (LUTS) and satisfaction among patients having diagnostic cystoscopy. 2021;16(32):69-72. DOI: https://doi.org/10.3126/ njog.v16i1.37523

\title{
Pattern of Lower Urinary Tract Symptoms (LUTS) and satisfaction among patients having diagnostic cystoscopy
}

\author{
Tarun Pradhan ${ }^{1}$, Amit Deo ${ }^{1}$, Raj Deb Mahato, ${ }^{1}$ Tulasa Basnet ${ }^{2}$ \\ ${ }^{1}$ Department of Obstetrics and Gynaecology, Birat Medical College \\ Teaching Hospital \\ ${ }^{2}$ Department of Obstetrics and Gynaecology, BP Koirala Institute of \\ Health Sciences
}

\section{ABSTRACT}

Aims: To study the pattern of LUTS during diagnostic cystoscopy and to evaluate patient's satisfaction using rigid cystoscopy with intra-urethral lignocaine gel.

Methods: Hospital based cross-sectional observational study done in all patients attending Department of Obstetrics and Gynecology with LUTS. Diagnostic cystoscopy was performed after using intra-urethral lignocaine gel. Patients profile and indications for cystoscopy were recorded; and VAS (Visual Analogue Scale) was used to assess procedure related pain. Data stored in MS Excel and descriptive analysis performed using SPSS 21.

Result: Forty-three patients were included in the study. The mean age of presentation was 45.77 years. Majority of the patients were pre-menstrual and with symptoms less than 5 year duration. Twenty-seven (62.8\%) patients had urgency as indication for cystoscopy followed by cystitis and recurrent urinary infection each $(16.3 \%)$. Only 2 patients had mixed urinary incontinence. Thirty -one $(72.1 \%)$ had mild discomfort, seven $(18.7 \%)$ moderate and 5(9.2\%)severe in visual analogue scale.

Conclusions: Urgency was found to be a frequent indication for diagnostic cystoscopy and use of rigid cystoscope using inra-urethral gel showed only mild discomfort to majority of patients.

Keywords: cystoscopy, lower urinary tract symptoms, visual analogue scale

\section{INTRODUCTION}

Diagnostic cystoscopy is frequently performed as day care procedure by urologists, gynaecologists and urogynaecologists for the lower urinary tract symptoms (LUTS) such as urgency, urge incontinence, sensation of incomplete voiding, urinary retention, treatment for recurrent urinary tract infections and chronic pelvic pain (due to interstitial cystitis). ${ }^{1}$

The choice of the cystoscope is a dilemma. Flexible cystoscope is getting more acceptability by clinician and patients for causing less discomfort but in low income country like ours where affordability for the instruments is important concern, flexible cystoscope is not routinely available. Disadvantage of rigid cys cystoscope though cheaper is more discomfort to the patient and may be costly due to need of anesthesia and prolong hospital stay. However, day care practice is feasible because of short female urethra to negotiate cystoscope and instillation of intraurethral anesthetic gel. ${ }^{2}$ Visual Analogue Scale (VAS) is used to measure pain and discomfort that uses calibration from zero as "no pain" to 10 as "extreme pain and discomfort".

Time required by anesthetic lignocaine gel for adequate anesthesia for tolerable cystoscopic insertion is reported to be at around 5 to 20 minutes. ${ }^{4,5}$ But till date there is no publications evaluating whether the topical spray has better anesthesia than lignocaine gel application. 
This study is evaluating the pattern of lower urinary tract symptoms (LUTS) and patient satisfaction during diagnostic cystoscopy after using intra-urethral lignocaine gel.

\section{METHODS}

A Hospital based cross-sectional observational study was conducted from August 2020 to February 2021 in the Department of Obstetrics and Gynecology, Birat Medical College Teaching Hospital after ethical approval from Institutional Review Committee (IRC). All the patients visiting out-patient department with urinary symptoms like urgency, urge incontinence, increased frequency, hesitancy, sensation of incomplete voiding, stress urinary incontinence, history of recurrent urinary tract infection and chronic pelvic pain were included in the study after informed consent. Sample collection was done by using total enumeration technique. The procedure was performed at minor operation theatre for diagnostic cystoscopy using rigid cystoscope, Karl Storze.

After positioning the patient in lithotomy position, following all aseptic precautions. Intra-urethral $2 \%$ lignocaine gel was instilled per urethra and left for 5 minutes. Diagnostic cystoscopy was performed with concomitant communication and real time visualization of cystoscopy screen to the patients. Appearance of urethral mucosa, mucosal co-aptation, urethra-vesical angle, bladder mucosa hyperemia, trabeculations and ureteric orifices were noted. After the procedure, patients were asked regarding degree of discomfort using visual analogue scale (VAS) and categorized by measuring $0-4$ as mild discomfort, 5-7 as moderate discomfort and 8-10 as severe discomfort.

All the variables were recorded in a proforma, then to MS Excel and later in SPSS window data sheet. Mean, frequency and percentage were calculated for descriptive parameters and Pearson's chi-square tests were performed for identification of relation between demographic variables with cystoscopy indication, findings and visual analogue scale.

\section{RESULTS}

Out of 8051 out-patients 43 diagnostic cystoscopies were performed for lower urinary tract symptoms. The mean age of patients with urinary symptoms was $45.77 \pm 21-75$ years and $17(39.5 \%)$ were at menopause. Thirty-six patients $(83.7 \%)$ had duration of symptom for less than 5 years; 14 (32.6\%) had lower segment cesarean section and five (11.6\%) had hysterectomy. [Table-1]

Majority presented with storage dysfunction like frequency $(93 \%)$, urgency $(79.1 \%)$, and urge incontinence $(55.8 \%)$. Participants also presented with complaints like burning micturition $(60.5 \%)$, sensa
Table-1: Socio-demographic profile

\begin{tabular}{clc}
\hline \multicolumn{2}{c}{ Variables } & $\mathrm{N}(\%)$ \\
\hline \multirow{2}{*}{ Age } & $20-40$ & $17(39.5)$ \\
(years) & $40-60$ & $9(46.6)$ \\
& $>60$ & $17(13.9)$ \\
\hline \multirow{3}{*}{ Parity } & $\mathrm{P} 0$ & $2(4.7)$ \\
& $\mathrm{P} 1$ & $6(14)$ \\
& $\mathrm{P}>1$ & $35(81.3)$ \\
\hline
\end{tabular}

tion of incomplete evacuation and pain lower abdomen both $(58.1 \%)$. Nine participants also presented with stress urinary incontinence and nocturia; and the most common indication urgency. [Table-2]

Table-2: Indication for Diagnostic Cystoscopy

\begin{tabular}{ll}
\hline Symptoms & $\mathrm{N}(\%)$ \\
\hline Urgency & $27(62.8)$ \\
Cystitis & $7(16.3)$ \\
Recurrent urinary infection & $7(16.3)$ \\
Mixed (stress+urge) incontinence & $2(4.6)$ \\
\hline
\end{tabular}

The visual analogue scale (VAS) score for the discomfort felt during diagnostic cystoscopy showed mild (0-4) in $31(72.1 \%)$, moderate (5-8) in 7 $(18.7 \%)$ and severe $(>8)$ in $5(9.2 \%)$. Most common bladder finding was various grades of trabeculations and there was no ulcer. [Table-3]

Table-3: Finding during cystoscopy

\begin{tabular}{lll}
\hline \multicolumn{2}{c}{ Findings } & $\mathrm{N}(\%)$ \\
\hline \multirow{2}{*}{ Trabeculation } & Mild & $8(18.6)$ \\
& Moderate & $20(46.5)$ \\
Urethra & Severe & $11(25.6)$ \\
Bladder mucosa & Hyperemia & $3(7)$ \\
Hemorrhagic spots & Hyperemia & $29(67.4)$ \\
& Present & $6(14)$ \\
\hline
\end{tabular}

Association was sought between various sociodemographic variables with severity of trabeculation, requirement of anti-muscarinics, indications of cystoscopy and measurement of discomfort using visual analogue scale (VAS). Indication for need of cystoscopy showed significant relation with advancing age. Anti-muscarinics use was significantly related with menopause status and participants having history of lower segment cesarean section (LSCS). Cystoscopic finding of severity of trabeculations was significantly related with participants having history of LSCS. Participants who had history of treatment for urinary tract infections (UTI) also showed significant relation with need of anti-muscarinic and requirement of diagnostic cystoscopy. [Table-4] 
Table-4: Correlation of sociodemographic variables

\begin{tabular}{lcccc}
\hline & $\begin{array}{c}\text { Trabecula- } \\
\text { tion }\end{array}$ & $\begin{array}{c}\text { Need of } \\
\text { Antimuscarinics }\end{array}$ & $\begin{array}{c}\text { Indication for } \\
\text { Cystoscopy }\end{array}$ & VAS \\
\hline Age & 0.62 & 0.28 & $\mathbf{0 . 0 4 9}$ & 0.72 \\
Parity & 0.35 & 0.65 & 0.91 & 0.94 \\
Menopause & 0.14 & $\mathbf{0 . 0 3}$ & 0.42 & 0.87 \\
Pre-menstrual & 0.06 & 0.07 & 0.32 & 0.54 \\
H/O LSCS & $\mathbf{0 . 0 4}$ & $\mathbf{0 . 0 3}$ & 0.054 & 0.46 \\
H/O Hysterectomy & 0.52 & 0.16 & 0.59 & 0.93 \\
H/O UTI treatment & 0.42 & $\mathbf{0 . 0 3 4}$ & $\mathbf{0 . 0 1 4}$ & 0.58 \\
Duration of symptoms & 0.26 & 0.33 & 0.572 & 0.44 \\
\hline
\end{tabular}

*Level of significance $p<0.05$.

\section{DISCUSSION}

Diagnostic cystoscopy is a useful procedure for various lower urinary tract symptoms in women of different age groups. Mean age in this study was 45.77 years like in the study done by Daneshpajooh et $\mathrm{al}^{6}$ (48.33 years in recurrent UTI and $52.2 \%$ of menopausal age group) but only $39.5 \%$ were at menopause in this study. Thirty-seven (42\%) had history of hysterectomy or prolapse surgery but in this study only five (11.6\%) had history of hysterectomy.

Urgency was the most frequent indication for cystoscopy followed by recurrent urinary tract infections and cystitis. The study on flexible and rigid cystoscopy on women by Gee JR et $\mathrm{al}^{7}$ showed hematuria and recurrent urinary tract infections as most common indication for cystoscopy. This difference may be due to difference in life style and different geographical population.

Patient satisfaction as measured by patient satisfaction questionnaire by Almallah $\mathrm{YZ}$ et $\mathrm{al}^{8}$ in study done for urinary tract infection and patients satisfaction after flexible cystoscopy and urodynamic evaluation showed $82.5 \%$ had better than expected, $12.4 \%$ had as expected and only $4.9 \%$ worse than expected. ${ }^{8}$ It was similar in this study on VAS as $72.1 \%$ had mild, $18.7 \%$ had moderate and $9.2 \%$ had severe discomfort.

Study on The effect of office based flexible and rigid cystoscopy on pain experience in female patients by Casteleijn et $\mathrm{al}^{9}$ showed hematuria as most common indication for cystoscopy followed by Lower Urinary Tract Symptoms (LUTS), recurrent urinary tract infection and incontinence being the last in the list in contrast to our study urgency and urge incontinence was the most common indications for cystoscopy. The study also showed Visual Analogue Scale (VAS) in patients using rigid cystoscope had score more than zero in majority $(71.7 \%)$ in contrast majority of the patients had only mild on VAS. There has been various proposal for reducing pain perception and increase tolerance of pain during procedure, like holding the patient's hand, listening to classical music or using TENS (Transcutaneous Electrical Nerve Stimulation)..$^{10-12}$ Real time visualization of procedure to patients during cystoscopy is thought to have effect in decreasing pain perception. Cystoscopy real-time self -visualization and its impact in patients pain perception by Daniel A et $\mathrm{al}^{13}$ showed real time visualization during cystoscopy diminished pain perception during patients third or more frequent cystoscopy. Basak S et $\mathrm{al}^{2}$ showed $96.3 \%$ patients fully satisfied with out-patient rigid cystoscopy using intra-urethral lignocaine gel. Similarly Agrawal V et $\mathrm{al}^{14}$ showed mental component more affected than physical component in rigid cystoscopy. ${ }^{14}$ Our study is limited by small sample size.

\section{CONCLUSIONS}

Urgency was found to be a frequent indication for diagnostic cystoscopy followed by other lower urinary symptoms and use of rigid cystoscope using intra-urethral gel can be used with only mild discomfort to patients.

\section{REFERENCES}

1. Lee JWS, Doumouchtsis SK, Jeffery S, Fynes MM. Evaluation of outpatient cystoscopy in urogynaecology. Arch Gynecol Obstet. 2009;279:631-635. DOI: 10.1007/s00404-0080773-6

2. Basak S, Johnson H, Pradhan A. Outpatient rigid cystoscopy: Is it acceptable to women? J Clin Urol. 2015;8(2):139-42. DOI: $10.1177 / 2051415814550840$

3. Wewers ME, Lowe NK. A Critical Review of Visual Analogue Scales in the Measurement of Clinical Phenomena. Res Nurs Health. 1990;13:227-36. $\quad$ PMID: 2197679. DOI: $10.1002 /$ nur.4770130405

4. Brekkan E, Ehrnebo M, Malmstrom PU, Norlen PU, Wirbrant A. A controlled study of low and high volume anesthetic jelly as a lubricant 
and pain reliever during cystoscopy. J Urol. 1991;146: 24-7. PMID: 2056598. DOI: 10.1016/ s0022-5347(17)37705-4

5. Goldfischer ER, Cromie WJ, Karrison TG, Naszkiewicz L, Gerber GS. Randomized, prospective, double-blind study of the effects on pain perception of lidocaine jelly versus plain lubricant during outpatient rigid cystoscopy. J Urol. 1997;157: 90-4. PMID: 8976223

6. Daneshpajooh A, Mirzaei M. Cystoscopy Findings in Females with Recurrent Urinary Tract Infections. Nephro-Urol Mon. $2018 ; 10$ (4):e61829. doi: 10.5812/numonthly.61829

7. Gee JR, Waterman BJ, Jarrard DF, Hedican SP, BruskewitzRC, Nakada SY. Flexible and Rigid Cystoscopy in Women. JSLS. 2009;13:135-8. PMID: 19660204

8. Almallah YZ, Rennie CD, Stone J, Lancashire MJR. Urinary Tract Infection and Patient Satisfaction after Flexible Assessment of efficacy of Transcutaneous Electrical Nerve Stimulation for Pain Management during Office-based flexible Cyctoscopy Cystoscopy and Urodynamic Evaluation. Adult Urol. 2000;56:37-9. PMID: 10869618. DOI: 10.1016/s0090-4295(00) 00555-0

9. Casteleijn NF, Vriesema JL, Stomps SP, van Balen OLWB, Cornel EB. The effect of Office based Flexible and Rigid Cystoscopy on pain experience in Female Patients. Invest Clin Urol. 2017;58:48-53. DOI: https://doi.org/10.4111/ icu.2017.58.1.48
10.Kwon WA, Lee JW, Seo HK, Oh TH, Park SC, Jeong HJ, et al. Hand-Holding during Cystoscopy Decreases Patient Anxiety, Pain, and Dissatisfaction: A Pilot Randomized Controlled Trial. Urol Int. 2018;100(2):222-7. doi: 10.1159/000485745 Epub 2017 Dec 22. PMID: 29275402.

11.Hruby G, Ames C, Chen C, Yan Y, Sagar J, Baron $\mathrm{P}$, et al. Assessment of efficacy of transcutaneous electrical nerve stimulation for pain management during office-based flexible cystoscopy. Urol. 2006;67(5):914-7. doi: 10.1016/j.urology.2005.11.043. PMID: 16698351 .

12. Raheem OA, Mirheydav HS, Lee HJ, Patel ND, Godebu E, Sakamoto K. Does Listening to Music During Office-Based Flexible Cystoscopy decrease Anxiety in Patients: A Prospective Randomized Trial. J Endourol. 2015;29(7):7916. DOI: $10.1089 /$ end.2015.0029

13.Padilla DAG, Gonzalez-Diaz A, Garcia-Gomez B, Villacampa-Auba F, Miranda-Utrera N, Rodriguez-Antolin A. Cystoscopy Real-Time SelfVisualization and It's Impact in Patient's Perception. J Endourol. 2019;33(4):309-13. DOI: 10.1089/end.2018.0768. PMID: 30793929

14. Agrawal V, Jha AK, Palmo D, Mohanty D. Post Procedure Effects of Diagnostic Rigid Cystoscopy. J Clin Diagnost Res. 2018;12(2):8-11. DOI: $10.7860 / J C D R / 2018 / 27283.1118$ 